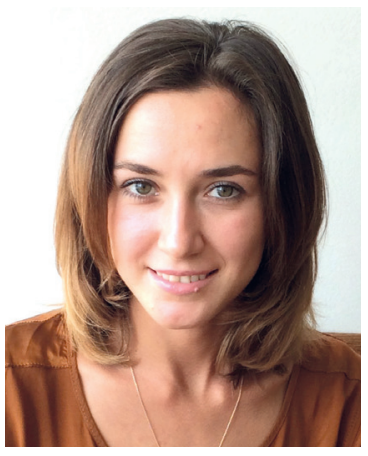

\section{Ревенко Анастасия Андреевна}

преподаватель Высшей школы (факультета) телевидения, Московский государственный университет

им. М. В. Ломоносова,

119991, г. Москва, ул. Ленинские горы, 1, стр. 51, e-mail: anastasia.a.revenko@yandex.ru

Anastasiya A. Revenko

Lecturer, High School of Television, Lomonosov Moscow State University, 1/51 Leninskie gory St., Moscow, 119991, Russian Federation, e-mail: anastasia.a.revenko@yandex.ru

\title{
ДЕЯТЕЛЬНОСТЬ СЕТЕВЫХ МЕДИАРЕСУРСОВ ПО ПОПУЛЯРИЗАЦИИ КУЛЬТУРНОГО НАСЛЕДИЯ РОССИИ В УСЛОВИЯХ ГЛОБАЛИЗАЦИИ КУЛЬТУРНОГО ПРОСТРАНСТВА
}

\footnotetext{
Аннотация. В статье подробно исследуется влияние глобализации культурного пространства на деятельность сетевых медиаресурсов по популяризации культурного наследия Российской Федерации, что представляется актуальным в современном информационным обществе и необходимым в аспекте преемственности поколений. В условиях глобализации и коммерциализации трансформируются не только содержание и типология СМК туристской тематики, но и их способы доставки и каналы распространения. Туристский медиапродукт за последнее десятилетие обрел собственную целевую аудиторию, источники фринансирования, изменил фоору подачи информации, концепцию, тематику, внешний вид, стал независим от территориальной и национальной принадлежности его издателя. Именно данные тенденции сыграли важную роль в развитии сетевых медиаресурсов туристской тематики. С целью более глубокого раскрытия темы автором приводятся определения понятий «глобализация СМК и массовой культуры», «культурное пространство», «информационное общество» и пр., данные ведущими исследователями СМК. Также в статье подробно рассмотрены основные российские и международные нормативные акты, направленные на учет и сохранение материального и духовного культурного наследия, - Федеральный закон «Об объектах культурного наследия (памятниках истории и культуры) народов Российской Федерации», «Хартия о сохранении цифрового наследия». Рассмотрены типологические особенности сетевых медиаресурсов - в целом, и туристских сетевых медиаресурсов - в частности. Автором сформулирована типология туристских сетевых медиаресурсов, которая включает в себя электронные версии периодических изданий; сайты телеканалов и телепрограмм о страноведении, туризме и путешествиях; личные страницы туристов, блоги и фрорумы; специализированные туристские порталы; сайты муниципальных организаций с разделами туристской тематики. Дается всестороння оценка каждого объекта. Предпринятый анализ предполагает подробное описание деятельности сетевых медиаресурсов
} 
туристской тематики, направленной на популяризацию культурного наследия России. Выделяются их основные достоинства и недостатки.

Ключевые слова. Культурное наследие, медиаресурс, тревел-журналистика, туристская журналистика, журналистика путешествий, глобализация, культурное пространство, туристские сетевые медиаресурсы.

Информация о статье. Дата поступления 6 июля 2016 г. ; дата принятия к печати 1 августа 2016 г.; дата онлайн-размещения 31 октября 2016 г.

\title{
ONLINE MEDIA RESOURCES AS A TOOL OF PROMOTING RUSSIAN CULTURAL HERITAGE IN THE PROCESS OF CULTURE GLOBALIZATION
}

\begin{abstract}
The article studies in detail the impact of globalization of cultural space on online media resources ability to promote the cultural heritage of the Russian Federation, which seems relevant in today's information society and is an essential aspect in terms of continuity of generations. In the context of globalization and commercialization not only the content and typology of tourism means of mass communication are transformed, but also their delivery methods and distribution channels. Tourist media product in the last decade has found its own audience, sources of funding, has changed the form of presenting information, its conception, topics, design, it has also become independent from the territorial and national identity of its publisher. These are the trends that have played an important role in the development of tourism online media resources. The author gives definitions of the terms "globalization of means of mass communication and mass culture», "cultural space», «information society", etc. in order to explain the subject better. These definitions are provided by the leading researchers in the field of means of mass communication. The article also discusses in detail the major Russian and international regulations aimed at keeping and preserving tangible and intangible cultural heritage, i.e. the Federal Law On objects of cultural heritage (historical and cultural monuments) of the Russian Federation peoples and Charter on the Preservation of the Digital Heritage. Typological features of online media resources are considered in general, and tourism online media resources in particular. The author formulates a typology of tourist online media resources, which includes electronic versions of periodicals; websites and television channels of area studies, travel and tourism; personal pages of travelers, blogs and forums; specialized tourism portals; tourism scitions of municipal organizations websites. It provides a comprehensive assessment of each object. The analysis carried out involves a detailed description of activities of the online trevel media resources, aimed at promoting the cultural heritage of Russia. Their main advantages and disadvantages are defined.

Keywords. Cultural heritage, online media resource, tourism journalism, travel journalism, globalization, cultural space, tourism online media resources.

Article info. Received July 6, 2016; accepted August 1, 2016; available online October 31, 2016.
\end{abstract}

Процессы глобализации информационного пространства и коммерциализации рынка оказывают влияние на всю систему СМК в целом, и на каждый ее элемент в отдельности.
СМК туристской тематики не стали исключением. В условиях глобализации и коммерциализации трансформируются не только их содержание и типология, но и способы доставки и 
каналы распространения туристского медиапродукта, который за последнее десятилетие обрел собственную целевую аудиторию, источники финансирования, изменил форму подачи информации, концепцию, тематику, внешний вид, стал независим от территориальной и национальной принадлежности его издателя. В эпоху глобализации активное развитие получают сетевые медиаресурсы туристской тематики. Это могут быть как электронные версии периодических изданий или программ, так и специализированные порталы, популяризирующие культурное наследие Российской Федерации.

Для более глубоко анализа деятельности сетевых медиаресурсов по популяризации культурного наследия России в условиях глобализации культурного пространства необходимо дать определение понятиям «глобализация СМК и массовой культуры» и «культурное пространство».

По мнению Е. Л. Вартановой, «теоретики глобализации исходят из того, что для современного человека география теряет значение, причем средства коммуникации играют в этом решающую роль. В результате, по мнению одних исследователей, СМК преобразуют личный опыт (Э. Гидденс, Уолтерс), по мнению других - опыт социальный (О. Бойд-Баррет и Т. Рантанен, П. Годинг и Харис и др.). Глобализация, как подчеркивают практически все ученые, писавшие на эту тему, это многомерный процесс, происходящий одновременно на нескольких уровнях. Это глобализация рынка, производства, фринансов, коммуникации, опирающихся на глобальную инфраструктуру. Последняя обеспечивает не только беспрепятственное круглосуточное движение финансовых потоков, но и потоков информации, включая глобальную рекламу. Понятие «информация» в данном контексте используется в самом широком смысле и включает в себя как сведения о рынках, потребителях, налоговых системах, так и символы, образы, понятия, единые для всего человечества. Последние фрормируют своего рода символическую среду, в которой свободно циркулируют потоки медиаконтента - вне зависимости национальных представителей их создателей. Общедоступность этой символической среды - в географическом и понятийном смысле - и есть глобализация в сорере СМИ и массовой культуры» [1, с. 128-129].

Глобализация является одним из решающих фракторов развития современных средств массовой коммуникации, в том числе и сетевых медиаресурсов туристской тематики, которые, в свою очередь, способствуют глобализации культурного пространства, а также взаимопроникновению культур на разных уровнях и этапах их становления и развития. М. Я. Сараф утверждает, что «культурное пространство выступает как способ и форма одновременного бытия и общения людей различных культур, как способ и форма взаимодействия и взаимопорождения этих культур» [2]. Основываясь на приведенных определениях, можно говорить о глобализации культурного пространства и культуры в целом, частью которых является культурное наследие. Стирание пространственных и временных границ, характерное в эпоху глобализации, позволяет говорить о формировании эфффективных условий для сохранения и популяризации культурных ценностей, например, посредством инорормационно-коммуникационных технологий (ИКТ), а также создания единого культурного пространства, позволяющего узнать о различных 
культурах и рассказывать о своей, осознавать свое место в историческом развитии всего мирового сообщества.

В нормативном порядке проводится ряд действий, направленных на учет и сохранение культурного наследия. Согласно ст. 15 Федерального закона «Об объектах культурного наследия (памятниках истории и культуры) народов Российской Федерации», «в Российской Федерации ведется единый государственный реестр объектов культурного наследия (памятников истории и культуры) народов Российской Федерации, содержащий сведения об объектах культурного наследия. Реестр представляет собой государственную информационную систему, подключаемую к инфраструктуре, обеспечивающей инорормационно-технологическое взаимодействие информационных систем, используемых для представления государственных и муниципальных услуг в электронной форме, и включающую в себя банк данных, единство и сопоставимость которых обеспечиваются за счет общих принципов формирования реестра, методов и формы ведения реестра» ${ }^{\text {. }}$ Сведения, содержащиеся в реестре объектов культурного наследия, являются основным источником информации о культурном наследии страны.

В октябре 2003 г. по инициативе ЮНЕСКО была принята «Хартия о сохранении цифрового наследия». Она утверждает возникновение нового вида наследия - цифрового, и подчеркивает, что «доступ к этому наследию создаст более широкие возможности для творчества, общения

1 Об объектах культурного наследия (памятниках истории и культуры) народов Российской Федерации : федер. закон от 25 июня 2002 г. № 73-Ф3 (ред. от 13 июля 2015 г.) \\Российская газета. 2002. 29 июня. и совместного использования знаний всеми народами». Согласно «Хартии», «цифровое наследие состоит из уникальных ресурсов человеческих знаний и форм их выражения. Оно охватывает ресурсы в области культуры, образования, науки... созданные в цифровом виде или переведенные в цифровую фрорму из существующих аналоговых ресурсов. Цифровые материалы включают тексты, базы данных, неподвижные и движущиеся изображения, звуковые и графические материалы, программное обеспечение и вебстраницы, представленные в широком и увеличивающемся диапазоне форматов. Они часто недолговечны и для того, чтобы их сохранить, требуются целенаправленные усилия на их производство, техническое производство и управление ими». Согласно ст. 9, «цифровое наследие по своей природе не имеет ограничений по времени, географии, культуре и формату. Обладая специфическими чертами, присущими той или иной культуре, оно, тем не менее, потенциально доступно любому человеку в мире. Меньшинство может общаться с большинством, отдельный человек - с аудиторией, которой является весь мир».

Данная выдержка из «Хартии - сохранении цифрового наследия» подтверждает справедливость приведенных выше утверждений ○ глобализации культурного пространства. Важным вопросом, о котором говорится в «Хартии», является доступ к цифровому наследию с учетом реалий глобализующегося мира. «Цель сохранения наследия заключается в том, чтобы оно оставалось доступным для общества. Соответственно, доступ к материалам цифрового наследия, особенно к тем, которые относятся к области общественного пользования, должен 
быть свободным от необоснованных ограничений». Также ЮНЕСКО поднимает вопрос утраты цифрового наследия. «Существует риск утраты всемирного цифрового наследия для последующих поколений. Факторы угрозы заключаются в старении техники и программного обеспечения, необходимого для доступа к цифровым материалам, неясность в отношении ресурсов, ответственности и способов технического обслуживания и обеспечения их сохранности, а также отсутствие соответствующего законодательства. Изменение в отношении к этим проблемам отстает от технологических изменений» ${ }^{1}$.

Информационному обществу характерно активное развитие информационных и компьютерных технологий. Под «информационным обществом» А. А. Калмыков понимает «глобальный экономико-политический, антропосоциальный и технологический проект, предполагающий управляемый цивилизационный переход к мировому общественному устройству, при котором доминирующую роль во всех областях жизни будет играть система массовых коммуникаций, реализованная с помощью компьютерных телекоммуникационных технологий, в частности технологий интернета» [3, с. 21]. Повсеместное продвижение ИКТ играет важную роль в деятельности, направленной на популяризацию, сохранение и охрану культурного наследия страны, так как обеспечивает более быстрые и эффрективные методы доставки данной информации в любой из ее регионов. Распространение знаний о собственной стране, посредством таких технологий, способ-

1 Хартия о сохранении цифрового наследия [Электронный ресурс] // Организация Объединенных Наций. URL : http: // www.un.org/ru/documents/decl_conv / conventions/digital_heritage_charter.shtml. ствует национальной идентификации личности, фрормированию патриотичного и толерантного отношения, особенно среди подрастающего поколения и молодежи. Также ИКТ позволяют преодолевать границы одной страны и распространять информацию об объектах культурного наследия за ее пределами, что способствует формированию положительного образа государства, подчеркивает его значимость в мировом наследии, привлекает туристические потоки, а значит и дополнительные финансовые потоки, которые можно направить на обеспечение сохранности памятников архитектуры, культуры, природы и пр.

Даже в самые тяжелые исторические периоды человечество стремилось сохранить духовные и материальные объекты культурного наследия, подчеркивая необходимость «межпоколенной трансляции культурных традиции» [4, с. 59]. Данный феномен Л. А. Пронина называет «культурной трансмиссией», основная мысль которой заключается в том, что «каждое поколение добавляет новые знания к уже накопленному богатству» [5], что подчеркивает необходимость не только учета, сохранения и популяризации культурного наследия, но и его дальнейшего развитие в данном направлении. В эпоху глобализации накопление, сохранение и обновление знаний о культурном наследии осуществляется, помимо традиционных способов (телевидение, пресса, радио, государственные проекты и пр.), посредством создания различных сетевых медиаресурсов туристской тематики.

Сетевые медиаресурсы туристской тематики представляют собой целостную систему, поддающуюся структурированию и включающую различные типы порталов, имеющих одинаковые или схожие черты, цели, 
задачи и функции. Для выявления и детализации закономерностей развития сетевых медиаресурсов туристской тематики, направленных на популяризацию культурного наследия, а также тенденций и особенностей функционирования, необходимо применение типологического анализа. Типологический метод исследования позволяет более точно установить соответствие того или иного сетевого медиаресурса научно обоснованной модели, отвечает на вопрос, какие типологические черты реализованы, а какие отсутствуют или проявляются недостаточно.

Типология туристских сетевых ресурсов как научная проблема практически не разрабатывалась учеными. Ю. Костыгова [6], И. Давыдов [7], Ф. Л. Косицкая [8] и др. проводили исследования по структуризации и типологизации журналистских интернет-порталов. Классификацией именно туристских порталов занимались такие исследователи как Н. А. Барабанова [9], А. Ю. Бычкова [10] и др. На их работы мы опирались при создании типологии туристских порталов, основным типологическим признаком которых выступает целевое назначение, - популяризация культурного наследия Российской Федерации.

Методы классификации электронных порталов, как и периодических изданий, могут быть различными. Усложняет процесс классификации интернет-СМК их специфическая природа, так как не всегда к ним применимы характеристики традиционных.

А. Костыгова предложила классифицировать интернет-порталы по нескольким критериям: «профессиональные - любительские; новостные - аналитические; общие - специализированные; по свободному или по платному распространению; по распространению непосредственно через сайты или путем уведомления через рассылку» [6]. Это общая типология, применимая ко всем видам интернет-СМК, следуя которой туристские сетевые ресурсы можно отнести к специализированным. Также внимания заслуживают порталы общего интереса, в которых отводится отдельное место разделам, посвященным туристской тематике.

Н. А. Барабанова классифицирует туристские инорормационнобиблиографические ресурсы «по уровню представленности в сети» и выделяет «информационно-поисковые системы общего назначения, содержащие туристскую информацию; специализированные туристские порталы и сайты; сайты профессиональных электронных изданий; сайты бронирований; сайты фирм туристических операторов и туристических агентств; сайты объектов туристской индустрии; сайты объектов туристского интереса; личные страницы путешественников, фрорумы, блоги» [9].

В центре нашего исследования находятся сетевые ресурсы, одной из основных функций которых является популяризация культурного наследия, которая, в свою очередь, реализуется посредством содержательных особенностей материалов. Для более глубокого анализа нами предложена следующая типология сетевых медиаресурсов туристской тематики:

- электронные версии периодических изданий (http://www.geo.ru/; http: / / www.vokrugsveta.ru/ и пр.);

- сайты телеканалов и телепрограмм о страноведении, туризме и путешествия (http://www.moуaplaneta.ru / и пр.);

- личные страницы туристов, блоги и форумы (http://kubatyan. livejournal.com/ и пр.); 
- специализированные туристские порталы (http://www.culture. ru/; http: / / www.museum.ru/ипр.);

- сайты муниципальных организаций с разделами туристской тематики.

Активное развитие сети Интернет приводит к тому, что крупные издания туристской тематики начинают создавать электронные версии и приложения для мобильных устройств, что не только увеличивает аудиторию, но и позволяет поддерживать с ней интерактивный диалог, обновлять данные в режиме реального времени, расширять свой контент, дополняя тем самым информацию, опубликованную в печатной версии. Электронные версии и приложения для мобильных устройств дают пользователям возможность иметь свободный доступ к предпочитаемому изданию в любом уголке мира в удобное ему время, достаточно подключиться к глобальной сети или загрузить электронную версию в свой гаджет заранее. Электронные версии предоставляются как на бесплатной, так и на платной основе. Часто на страницах издания туристской тематики читатель встречает отсылки на сайт: «подробнее об этом и многом другом читайте на нашем сайте». Все крупные издания туристской тематики имеют электронные версии - «Вокруг света» (http: / / www. vokrugsveta.ru/), GEO (http:// www.geo.ru/), National Geographic (http: / / www.nat-geo.ru/) и пр.

Развитие он-лайн вещания способствовало активному распространению программ о путешествиях и туризме в глобальной сети, привлечению все большего числа зрителей, давая им возможность посмотреть пропущенный выпуск или пересмотреть понравившийся, а также останавливать его, перематывать, делиться с друзьями и так далее. Например, часть выпусков телепрограммы «Клуб кинопутешествий» («Клуб путешествий») с 1977 по 1992 г. хранится на видеопленке в Гостелерадиофонде, из них только часть выпусков была оцифрована и выложена в Интернет. Записи после 2000-х гг. найти в сети легче. Тем не менее с прекращением выхода программы «Клуб кинопутешествий» был закрыт и сайт, что привело к потере большого количества выпусков. Благодаря процессам глобализации, современные передачи о путешествиях и туризме не повторяют печальный опыт «Клуба путешественников» - теперь любой выпуск доступен пользователям сети Интернет независимо от временных и пространственных характеристик. Свои электронные версии имеют практически все телеканалы и передачи. Программы туристской тематики в сети Интернет размещены не только на их официальных сайтах, но и на различных видео-порталах. Например, любой человек, имеющий выход в Интернет, может обратиться за старым или, наоборот, свежим выпуском необходимой программы к порталу www.youtube.com, где иx размещают как сами создатели, так и обычные пользователи.

Электронные версии туристской прессы, он-лайн вещание программ о туризме и путешествиях дают возможность доступа к материалам из любого уголка мира в любое время, тем самым, с одной стороны - расширяя свою аудиторию, а с другой стороны - способствуя популяризации культурного наследия.

Помимо он-лайн вещания туристских каналов и программ, а также электронных версий периодических изданий о туризме и путешествиях, в сети активно развивается «пользовательская» или «гражданская журналистика» [11]. «Геоблогеры» 
наполняют свои «электронные дневники» рассказами о собственных путешествиях, делятся впечатлениями, рекомендациями, фотографиями, видео и пр. Также к ведению блогов прибегают различные СМК туристской тематики, тем самым расширяя свою аудиторию и способствуя интерактивному взаимодействию.

Хорошим примером качественной пользовательской журналистики путешествий является клуб путешественников телеканала «Моя планета». Он представляет собой объединение людей, живущих по всему миру, которые имеют возможность публиковать репортажи о своих путешествиях на сайте «Моей планеты», получать комментарии и, в свою очередь, комментировать чужие записи. Перед публикацией репортажа на сайте происходит его рецензирование, которое подразумевает под собой проверку материала на достоверность, уникальность, отсутствие рекламы. «Репортаж - это не запись в личном блоге. Если материал не отвечает тематике клуба, не содержит ценной информации или неправильно оформлен, он будет скрыт и отправится на «переоформление». Вы получите уведомление с пояснением причины. После исправления ошибок вы сможете опубликовать материал повторно» ${ }^{1}$. Такой подход к подбору контента сайта «Моя планета», даже на уровне клуба путешественниковлюбителей, говорит о добросовестном отношении его создателей к своей работе, так как недостаточно просто иметь собственный медиаресурс, необходимым является и его качественное информационное наполнение. Помимо этого, в сети представлены различные блоги и фо-

1 Клуб моя планета [Электронный ресурс] // Телеканал Моя планета. URL : http: / / www.moya-planeta.ru/club/. румы туристской тематики, созданием которых занимаются как профессионалы отрасли туризма, так и обычные любители.

Существует ряд специализированных сетевых медиаресурсов, посвященных материальным и духовным объектам культурного наследия Российской Федерации, которые и представляют наибольший интерес для нашего исследования, являясь их мощнейшими популяризаторами, «Музеи России», «Культура. Рф», «Российская сеть культурного наследия» и др.

Электронный ресурс «Музеи России» (www.museum.ru) содержит в себе информацию более чем о 3 тыс. российских музеев, что говорит о глобальных масштабах работы, проделанной его создателями. Каждому музею отведена отдельная страница, где указана подробная инорормация о нем - телефон и адрес, схема проезда, режим работы, стоимость входного билета, ссылка на официальный сайт, афиша на ближайшее время, памятные даты и ежегодные мероприятия, краткое описание музея и его история, наиболее ценные (уникальные) коллекции, виды экскурсий, дополнительные услуги (киоски, кафе, кинозалы и т. п.), перечень должностных лиц и их контактные данные и пр. Стоит отметить удобную навигацию по сайту: пользователь может выбрать музей, задавая различные параметры - название, город, тип, рейтинг и т. п. Помимо этого, на форуме сайта «Музеи России» поднимаются важные вопросы культуры (статья «Молчание - знак согласия?»: «В ночь с 18 на 19 июня в Москве были разрушены экскаваторами два исторических здания - фллигель усадьбы Глебовых-Стрешневых-Шаховских на Большой Никитской, 19/16 и деревянный дом Феоктистовых на Большой Ордынке, 42»), где можно не только 
увидеть мнения, но и высказать свое. Также пользователь может ознакомиться с галереей, насчитывающей более 80 тыс. изображений, новостями культуры, перечнем сайтов (более 1 тыс.) о музеях - в частности, и культуре - в целом, анонсами культурных событий (раздел «Афиша») и новостями из жизни музеев.

Сетевой медиаресурс «Музеи России» является примером качественного информационного наполнения за счет разнообразия информации, представленной на сайте, ее объемов и полноты. К недостаткам можно отнести слабое дизайнерское оформление. При переходе на сайт «Музеи России» складывается впечатление, что он создан по элементарным шаблонам, доступным любому пользователю сети Интернет. Данный факт может оттолкнуть потенциального гостя ресурса, вызвать сомнение в достоверности предоставляемой информации, так как складывается впечатление, что сайт создан не профессионалами, проделавшими кропотливую работу и проверившими всю информацию на достоверность, а любителями.

Помимо информации о музеях, пользователь сети Интернет может обратиться к услугам виртуальных музеев, отправившись в удаленное путешествие по залам, например, Эрмитажа или Третьяковской галереи. Н. Л. Панина дает следующие определение «виртуального музея»: «созданная с помощью компьютерных технологий модель музея, реального или существующего исключительно в виртуальном пространстве», и подчеркивает, что «значение термина до сих пор вызывает острые дискуссии» [12, с. 9]. К значительным плюсам виртуальных музеев относится то, что он позволяет объединить сразу несколько коллекций, которые невозможно совместить в реальной жизни, а также дает возможность посетить музей (хоть и виртуально) людям, находящимся в других уголках страны или мира, или имеющим различные физические особенности, составить представление о реальном музее, его экспонатах. «Это приводит к стиранию границ между центром и периферией (провинцией), а значит, человек имеет возможность интегрироваться в мировые и культурные процессы» [5].

Значительный интерес, на наш взгляд, представляет портал культурного наследия России - «Культура. РФ» (www.culture.ru), популяризирующий как материальные, так и нематериальные объекты культурного наследия Российской Федерации. Медиаресурс создан при поддержке Министерства культуры Российской Федерации. Любой пользователь сети Интернет посредством портала «Культура.РФ» может познакомиться с новостями культуры и афишей событий, посмотреть фиильмы и телеверсии спектаклей, узнать о готовящихся лекциях или ознакомиться с материалами уже прошедших. Отдельного внимания заслуживают разделы «Музеи», «Театры» и «Традиции». Вкладка «Театры» содержит не только каталог он-лайн спектаклей, но и информацию о театрах России контактные данные (адрес, телефон, схему проезда и ссылку на официальный сайт), историю создания и развития, особенности и пр., а также телеверсии спектаклей (если таковые имеются), идущих в выбранном театре. На сайте содержится около 680 он-лайн спектаклей, что, конечно, является незначительным в сравнении с тем количеством спектаклей, которые идут во всех театрах страны.

На данном примере можно убедиться в том, что создателям сайта «Культура.РФ» предстоит еще долгий и кропотливый труд по созданию 
контента (не только театрального, но в целом всего - о музеях, достопримечательностях и пр.), освещающего культурное наследие, и наполнению им портала. Необходимо объединение всех регионов России с целью формирования контента о наследии каждого уголка страны в отдельности, которое является частью всероссийского, а также всемирного наследия. В результате организованных действий с течением времени сорормируется полноценный виртуальный реестр материальных и нематериальных объектов культурного наследия Российской Федерации, поддержание жизнедеятельности которого, его обновление и дополнение предстоит возложить на себя и принять как необходимость будущим поколениям.

Также нематериальное наследие России представлено на сайте «Культура.РФ» в разделе «Традиции». Рубрика рассказывает о мифологических представлениях и верованиях, этнографических комплексах (обряды, празднества, трудовые практики), народном исполнительстве (словесные, вокальные, инструментальные, хореографические и пр.), традиционных технологиях (ремесла, изготовление одежды, обуви и т. п., приготовление традиционной пищи). Здесь пользователь может не только прочитать об объектах нематериального наследия, но и послушать их («Песенное наследие Михаила Адамова из станицы Краснодонецкой Белокаметвенского района Ростовской области») и посмотреть («Женский рыболовный промысел на Вашке»). Опять же в разделе представлено незначительное число информации, количество которой, исходя из опыта длительного пользования сайтом, не увеличивается и не обновляется.

Значительную роль в популяризации культурного наследия должны играть сайты администраций регионов Российской Федерации. На наш взгляд, каждый такой электронный портал должен иметь отдельный раздел, посвященный туризму в регионе: рассказывать о местных достопримечательностях, традициях, природных и культурных объектах, предлагать туристские маршруты и пр. Ведь региональные памятники наравне с фредеральными являются национальным наследием Российской Федерации и мира в целом. Их популяризация необходима среди населения России. Огромные масштабы нашей страны хранят в себе множество различных этносов, традиций, природных и культурных ценностей и пр., о которых необходимо рассказывать ее многочисленному населению, способствуя популяризации знаний, культурному и интеллектуальному развитию, самоидентификации нации.

Сайты администраций города достаточно часто содержат сведения о своих достопримечательных местах, чем помогают гостям города формировать свое времяпрепровождение так, чтобы провести его с пользой, «прочувствовать» атмосореру выбранного места, его особенности и традиции, ощутить себя частью многообразной страны. К сожалению, разделы сайтов, посвященных туристской информации, администраций городов характеризуются невысоким качеством. К недостаткам можно отнести неполноту или избыточность информации, еe неструктурированность, отсутствие оперативного обновления и пр. Сложившаяся ситуация не соответствует современному состоянию общества эпохи глобализации. Данные недостатки можно объяснить отсутствием обученных кадров, единых стандартов ведения реестра объектов наследия, а также тем, что сбор сведений о туристских ресурсах является сложным и трудоемким процессом. 
Проанализировав деятельность основных сетевых медиаресурсов о культурном наследии России, можно говорить о том, что государством принимаются меры, направленные на учет, сохранение, охрану, трансляцию и популяризацию материальных и нематериальных ценностей. Формируются реестры, ведущие учет объектов культурного наследия, создаются виртуальные каталоги музеев, достопримечательностей, театров и других культурных мест. Виртуальные коллекции становятся доступны не только в виде описаний и фотографий, но и, например, в режиме он-лайн посещения или трансляции. На основе театральных спектаклей создаются их телеверсии, доступные на различных сайтах, в том числе и на портале культурного наследия России «Культура РФ». Различные традиции, обряды, ремесленный труд, празднества и т. п. доступны в формате видео, что является более увлекательным и привлекающим вниманием, чем простой текст. Данные тенденции способствуют не только удаленному доступу к наследию страны из любых уголков мира, стиранию пространственных и временных границ, но и распространению знаний и повышению культурного уровня широких слоев населения, созданию условий для самообразования. Тем не менее, анализ основных сетевых медиаресурсов, популяризирующих культурное наследие, выявил ряд минусов. Наличие уникальных культурных и природных объектов, а также различных нематериальных ценностей на территории Российской Федерации не делает их популярными «по умолчанию». Для их актуализации и продвижения требуется предпринимать ряд мер по созданию определенных образов, в которых важную роль играют история, культурные традиции, эпос и пр. На наш взгляд, сетевым медиа- ресурсам туристской тематики необходимо создание электронных карт, наличие которых способствовало бы формированию систематизированного свода информации о культурном наследии, а также наглядно демонстрировало его географическое расположение и глобальные масштабы. Также обращаясь к определенным разделам специализированных сайтов туристской тематики, мы столкнулись с таким явлением, как неполнота информации, что может искажать представление аудитории об объектах культурного наследия. Это выражается в отсутствии (или в очень скудном присутствии) информации и иллюстраций об объектах культурного наследия. Складывается впечатление, что при создании материалов о том или ином объекте отсутствует взаимодействие между создателями статьи и хранителями объекта, в качестве которых могут выступать муниципальные организации и т. п. Так, к примеру, обращаясь к информации о Художественном музее города Хабаровска на портале «Культура.Рф», мы получаем всего несколько фотографий экспонатов и пару предложений о них, хотя данный объект хранит в своих стенах значительное число артефактов, а полную информацию о них и о самом музее может получить любой желающий посредством экскурсионного обслуживания. Это говорит о слабом взаимодействии администрации сайта и местных органов культуры, что удивительно, если учитывать то, что сетевой ресурс «Культура.РФ» создается не простой инициативной группой, а профессионалами при поддержке Министерства культуры Российской Федерации.

Сбор сведений об объектах культурного достояния - сложный и трудоемкий процесс, требующий значительного количества времени, с одной стороны, также требует от- 
ветственного отношения, с другой стороны. В эпоху глобализации технические сложности отступают на второй план. ИКТ являются вспомогательным инструментом, с помощью которого должен создаваться качественный информационный ресурс, каждый объект которого имеет полное и достоверное описание, сопровождается информацией рекомендательного и справочного характера, иллюстрациями высокого качества, картами и другими необходимыми сведениями. Только такой подход к созданию сетевых медиаресурсов туристской тематики будет способствовать популяризации культурного наследия Российской Федерации.

В эпоху глобализации культурного пространства наследие представляет собой то, что интересует каждого и принадлежит всем. Предпринимае- мые шаги нельзя недооценивать. На последующие поколения ложится большая ответственность по продолжению начатой деятельности - обогащению уже созданных реестров, выработке единых технических и других стандартов создания качественного инорормационного контента, обучению кадров, способных к такой деятельности и т. д. В эпоху глобализации и присущих ей процессов информатизации и компьютеризации общества формирование виртуальных ресурсов, популяризирующих культурное наследие, является необходимым. Дублирование реальных объектов наследия цифровым выступает в качестве важной составляющей в вопросах учета, сохранения, охраны и трансляции его будущим поколениям с целью дальнейшей культурной трансмиссии.

\section{СПИСОК ИСПОЛЬЗОВАННОЙ ЛИТЕРАТУРЫ}

1. Основы медиабизнеса : учеб. пособие / под ред. Е. Л. Вартановой. - М. : Аспект Пресс, 2009. - 360 c.

2. Сараф М. Я. Культурное пространство как предмет исследования [Электронный ресурс] / М. Я. Сараф / / Пространство и Время. - 2011. - № 4. - Режим доступа : http://cyberleninka.ru/article/n/kulturnoe-prostranstvo-kak-predmet-issledovaniya.

3. Калмыков А. А. Интернет-журналистика : учеб. пособие / А. А. Калмыков, Л. А. Коханова. - М. : Юнити-Дана, 2005. - 383 с.

4. Захарова О. В. Этнографический музей и его виртуальное представительство в контексте формирования культурного опыта современного поколения / О. В. Захарова // Создание официальных сайтов учреждений культуры и образования: теория и практика : сб. науч. тр. / под ред. Н. И. Гендина, Н. И. Колкова. - СПб. : Профессия, 2015. - 384 с.

5. Пронина Л. А. Информационные технологии в сохранении культурного наследия [Электронный ресурс] / Л. А. Пронина // Аналитика культурологии. - 2008. № 3 (12). - Режим доступа : http://cyberleninka.ru/article/n/informatsionnye-tehnologiiv-sohranenii-kulturnogo-naslediya.

6. Костыгова Ю. Сетевые СМИ: занимательная типология / Ю. Костыгова // Мир Internet. - 2002. - № 4. - С. 20-23.

7. Давыдов И. Масс-медиа российского интернета. Основные тенденции развития и анализ текущей ситуации : аналит. докл. [Электронный ресурс] / И. Давыдов. - Режим доступа : http://lib.rin.ru/doc/i/99288p.html.

8. Косицкая Ф. Л. Жанровая палитра фрранцузского туристического дискурса / Ф. Л. Косицкая / / Вестник Томского государственного педагогического университета. 2013. - № 3 (131). - С. 192-195.

9. Барабанова Н. А. Библиографический аспект методики формирования системы информационного сопровождения субъектов туристской деятельности / Н. А. Барабанова // Известия Самарского научного центра РАН. Социальные, гуманитарные, медикобиологические науки. - 2010. - № 3-3. - С. 570-674.

10. Бычкова А. Ю. Анализ интернет-ресурсов туристских предприятий / А. Ю. Бычкова, Е. Н. Карчевская / / Псковский регионологический журнал. - 2010. — № 9. - С. 66-70. 
11. Показаньева И. В. Проблемное поле трэвел-журналистики как явления современного медиапространства [Электронный ресурс] / И. В. Показаньева // Медиаскоп. 2013. - № 3. - Режим доступа : http://www.mediascope.ru/node/1385.

12. Организация информации о культурном наследии в сети Интернет : учеб. пособие / Н. Л. Панина, Ю. А. Крейдун, В. В. Казаков, Н. Ю. Бартош. - Барнаул : Изд-во Алт. ун-та, 2014. - 143 с.

\section{REFERENCES}

1. Vartanova E. L. (ed.). Osnovy mediabiznesa [Basics of Media Business]. Moscow, Aspekt Press Publ., 2009. 360 p.

2. Saraf M. Ya. The cultural space as a research. Prostranstvo $i$ Vremya = Space and Time, 2011, no. 4. Available at: http://cyberleninka.ru/article/n/kulturnoe-prostranstvo-kak-predmet-issledovaniya. (In Russian).

3. Kalmykov A. A., Kokhanova L. A. Internet-zhurnalistika [Internet Journalism]. Moscow, Yuniti-Dana Publ, 2005. 383 p.

4. Zakharova O. V. Ethnographic Museum and its Virtual Representation in the Context of Shaping Cultural Experience of the Modern Generation. In Gendin N. I., Kolkov N. I. (eds). Sozdanie ofitsial' nykh saitov uchrezhdenii kul'tury i obrazovaniya: teoriya i praktika [Creating Official Websites of Cultural and Educational Institutions: Theory and Practice]. Petersburg, Professiya Publ., 2015. 384 p. (In Russian).

5. Pronina L. A. Information Technologies as a Tool of Preserving Cultural Heritage. Analitika kul'turologii = Analytics of Cultural Studies, 2008, no. 3 (12). Available at: http://cyberleninka.ru/article/n/informatsionnye-tehnologii-v-sohranenii-kulturnogo-naslediya. (In Russian).

6. Kostygova Yu. Network Mass Media: Engaging Typology. Mir Internet = World Internet, 2002, no. 4, pp. 20-23. (In Russian).

7. Davydov I. Mass-media rossiiskogo interneta. Osnovnye tendentsii razvitiya i analiz tekushchei situatsii [Russian Internet Mass Media: Main Tendences for Development and Current State Analysis]. Available at: http://lib.rin.ru/doc/i/99288p.html. (In Russian).

8. Kositskaya F. L. Palette of Speech Genres of the French. Tourist Discourse. Vestnik Tomskogo gosudarstvennogo pedagogicheskogo universiteta = Tomsk State Pedagogical University Bulletin, 2013, no. 3 (131), pp. 192-195. (In Russian).

9. Barabanova N. A. System of a travel entity information support: bibliographic aspect of formation techniques. Izvestiya Samarskogo nauchnogo tsentra RAN. Sotsial' nye, gumanitarnye, mediko-biologicheskie nauki = Izvestiya of the Samara Russian Academy of Sciences Scientific Center. Social, Humanitarian, Medicobiological Sciences, 2010, no. 3-3, pp. 570-674. (In Russian).

10. Bychkova A. Yu., Karchevskaya E. N. Internet Resources of Tour Companies Analysis. Pskovskii regionologicheskii zhurnal= Pskov Region Studies Journal, 2010, no. 9, pp. 66-70. (In Russian).

11. Pokazan'eva I. V. Problem field of travel journalism as a phenomenon of contemporary media environment. Mediaskop, 2013, no. 3. Available at: http://www.mediascope.ru/ node/1385. (In Russian).

12. Panina N. L., Kreidun Yu. A., Kazakov V. V., Bartosh N. Yu. Organizatsiya informatsii o kul'turnom nasledii v seti Internet [Representing Information on Cultural Heritage in the Internet]. Barnaul, Altai State University Publ., 2014. 143 p.

\section{БИБЛИОГРАФИЧЕСКОЕ ОПИСАНИЕ СТАТЬИ}

Ревенко А. А. Деятельность сетевых медиаресурсов по популяризации культурного наследия России в условиях глобализации культурного пространства / А. А. Ревенко // Вопросы теории и практики журналистики. - 2016. - T. 5, № 4. - C. 641-653. - DOI: $10.17150 / 2308-6203.2016 .5(4) .641-653$.

\section{REFERENCE TO ARTICLE}

Revenko A. A. Online media resources as a tool of promoting Russian cultural heritage in the process of culture globalization. Voprosy teorii $i$ praktiki zhurnalistiki $=$ Theoretical and Practical Issues of Journalism, 2016, vol. 5, no. 4, pp. 641-653. DOI: 10.17150/23086203.2016.5(4).641-653. (In Russian). 